\title{
A STUDY OF THE ERYTHROCYTE CURVE AT VARIOUS AGES AND ITS RELATIONSHIP TO HEMOGLOBIN CURVE
}

\author{
LAURENCE HAMPSON MAYERS, A.M., M.D. \\ CHICAGO
}

Numerous studies made on the blood of new-born infants have fairly well established the fact that the number of their erythrocytes per cubic millimeter is much higher than it is in the adult. Furthermore, a review of the results of hemoglobin determinations in new-born infants shows a much higher hemoglobin content than is found in adult life. The high hemoglobin content rapidly falls.

Williamson, in a spectrophotometric analysis of 919 cases, shows in his tables that the hemoglobin of the new-born infant averages 23.2 $\mathrm{gm}$. hemoglobin per hundred c.c. of blood. The hemoglobin falls rapidly and by the end of the second month the reading is $18.3 \mathrm{gm}$. At the end of the fifth month it is $13.7 \mathrm{gm}$., and then remains practically constant during the next few months, falling to $12.5 \mathrm{gm}$. at the end of the first year. From this point up to the sixth year there is a steady ascent, when it approximates the height of adult life.

Several factors, singly or in combination, may be the cause of this fall, i. e., a sufficient decrease in the number of corpuscles or a decrease in the hemoglobin or a combination of both phenomena. For a study of the problem it was necessary to establish this variation in relation to color index of new-born infants and for the early days and months of their lives. Periods conforming to the age periods of the hemoglobin curve were selected for comparison.

Burker's Zeiss hemocytometer, ${ }^{1}$ an approved apparatus for the more accurate counting of erythrocytes than is possible by the Thoma-Zeiss apparatus, was used in all the counts. The principles involved are somewhat different from those in force with the latter apparatus. Hayem's solution is used as the diluting fluid. Toison's solution is not satisfactory for use with the Burker counting chamber as its viscosity is too great. The corpuscles settle rapidly in Hayem's fluid as the specific gravity of the fluid is 1.015 , whereas that of the erythrocytes is 1.090. The Thoma-Zeiss capillary pipets were used. The blood was thoroughly mixed with the diluting fluid within the mixing chamber by tapping the pipet against the finger for five minutes.

In the older counting chamber the floor of the chamber is circular and the counting is done in the center of this space. The corpuscles are, therefore, counted in the center of a capillary circular film, where, on account of surface tension, their number is slightly greater than elsewhere. This source of error is avoided in the new counting cham-

1. Burker: Pflüger's Arch. f. d. ges. Physiol. 107:426, 1905. 


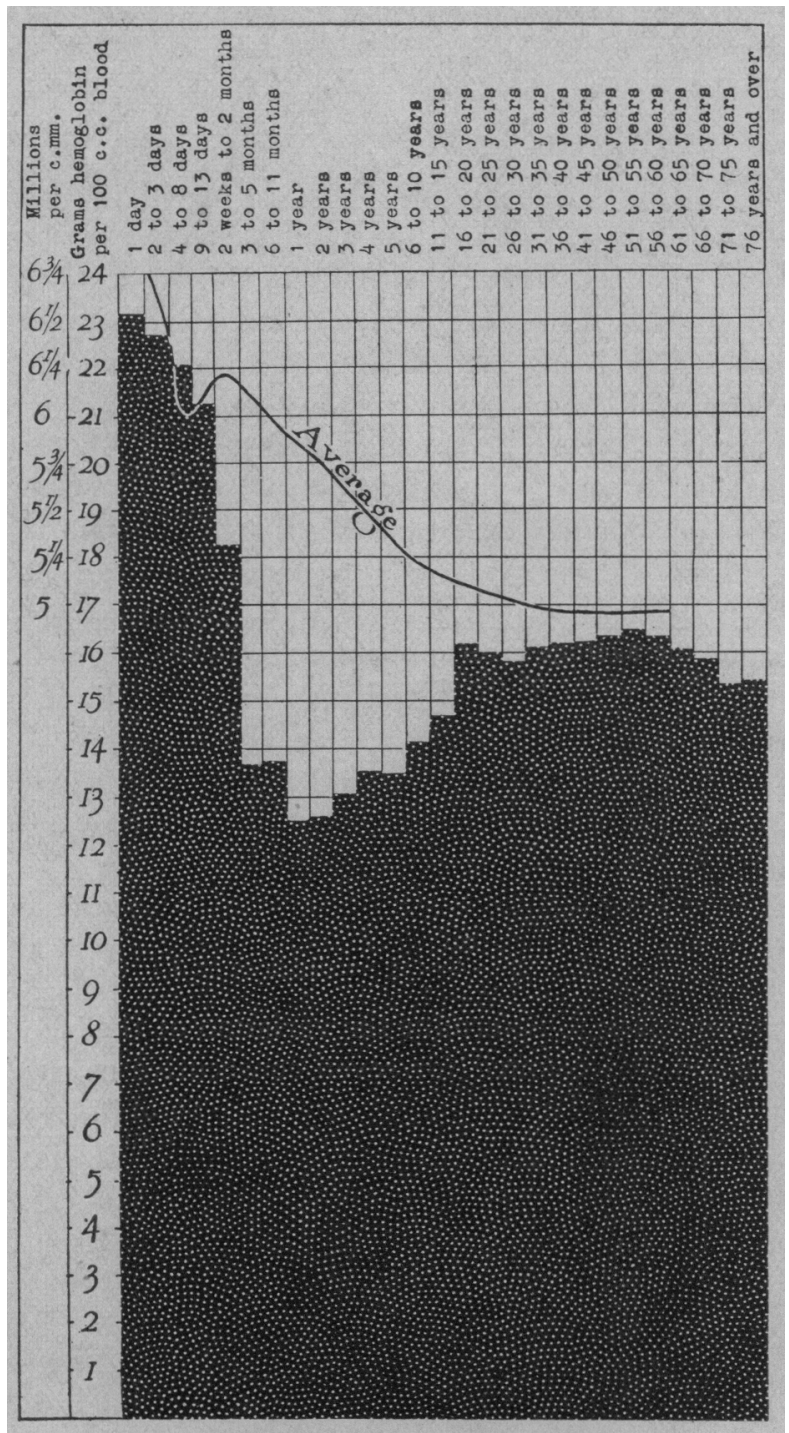

Fig. 1. - The solid black line indicates grams of hemoglobin per 100 c.c. of blood in persons ranging in age from one day to over 76 years. The curved line shows the average erythrocyte count at different ages to show the relationship between the number of erythrocytes and their hemoglobin content. 
ber, in which the floor is represented by the upper surface of a glass $25 \mathrm{~mm}$. long and $5 \mathrm{~mm}$. wide, which is rounded off at both ends and divided into two portions by a groove $1.5 \mathrm{~mm}$. wide through the center. At each side of the floor piece, separated from it by a groove, is a glass plate $7.5 \mathrm{~mm} . \times 21 \mathrm{~mm}$., of such height that the space between the floor of the cell and the cover glass placed across the plates is $0.100 \mathrm{~mm}$. A cover glass $23 \mathrm{~mm}$. long and $21 \mathrm{~mm}$. wide, with rounded, polished edges, is used, so that the rounded edges of the floor project beyond it. The chamber is provided with clamps to press the cover glass firmly on both plates. The same pipets, counting chamber and cover glass were used in all this series of counts.

To determine the accuracy of my blood enumeration, I counted my own blood for five counts over a period of seven hours. Eighty squares were counted. The result of the counts and a computation of the average error by method of Gauss was as follows:

Let $d$ equal the variation from the average.

Let $\mathrm{Sd}^{2}$ equal the sum of the squares of the individual variations.

Let $\mathrm{Fm}$ equal the average error of the average value.

Let $\mathrm{N}$ equal the number of observations.

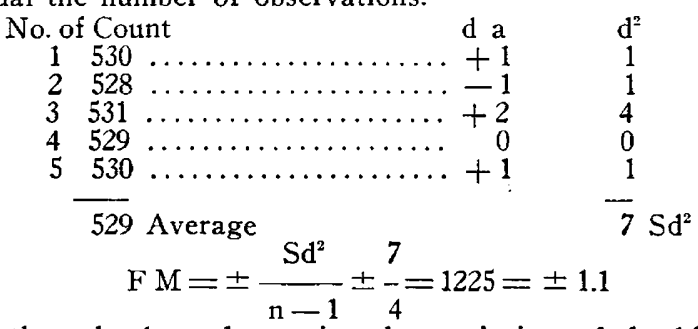

As a further check to determine the variation of the blood from day to day, my blood was counted for seven consecutive mornings.

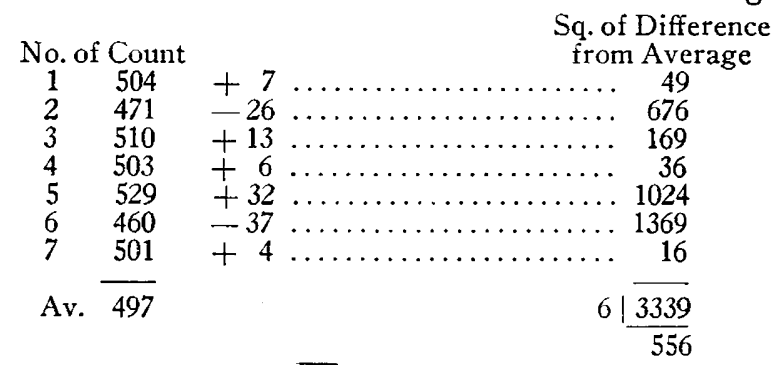

$$
\sqrt{556}= \pm 23.6
$$

The average error $= \pm$ the $\sqrt{\frac{\mathrm{SD}^{2}}{\mathrm{~N}-1}}$ in which $\mathrm{SD}^{2}$ is the sum of the square of the differences of the individual counts from the average count and $\mathrm{N}=$ the number of counts. Number of counts is seven.

$$
\text { Average error }= \pm \sqrt{\frac{S^{2}}{N-1}}=\frac{3339}{6}= \pm 23.6
$$


Blood was obtained from the right great toe in each instance. The toe was washed with alcohol and thoroughly dried. A sharp cataract knife was used to get a free flowing drop, without pressure. The first drop was wiped away and blood for the counting secured from the second drop. The children chosen were all apparently well nourished and healthy. The cases were taken from the maternity wards of Cook County and St. Luke's Hospitals and from private cases.

It is generally conceded that there is a polycythemia at birth and that there is an increase in the first twenty-four hours. There is much diversity of opinion as to the actual number found in a cubic millimeter of blood. The average number of red blood corpuscles per cubic millimeter based on the investigations of physiologists and pathologists, is $5,742,000$ red blood corpuscles per cubic millimeter of blood. The majority of the workers' conclusions for infants were based on comparatively few cases. Hayem ${ }^{2}$ and Sorensen cite one case each. Buchot and Dubrisay ${ }^{3}$ show $4,300,000$ as an average in six cases; Otto, ${ }^{4}$ four cases averaging 6,165,000; Schwinger, ${ }^{5} 5,080,765$ and Schiff, ${ }^{6} 5,825,000$ in single counts. Fehrsen ${ }^{7}$ observed forty casesminimum 6,047,000, maximum 7,250,000. The majority of these observers used the dilution method and counted with a Thoma-Zeiss apparatus. Fehrsen's forty subjects were examined on the first and tenth days of life. Only four subjects were examined within the first two hours and nineteen were examined between the tenth and twentieth hours, with an average of $5,898,000$. Woino and Dransky ${ }^{8}$ observed twenty-nine cases. Seven of these were not at full term and five were pathological. Six counts were made on babies before they began to breathe. His conclusions are in general similar to those of Hayem, Lepin and Schiff, namely, the number of red cells per $\mathrm{cm}$. in the newborn is considerably higher than in adults and figures exceeding $7,000,000$ were often obtained. He was unable to confirm the statement of Hayem and Lepin about the strict dependence between the changes in the number of red cells and the weight of the infant. This bears out my own conclusions, as I observed no relation between the number of red cells and the weight of the infant.

2. Hayem, Georges: Du Sang et de ses alterations anatomiques, Paris, 1889 , pp. 30 et seq.; 189.

3. Buchot and Dubrisay: Gaz. méd. de Par. 168, 1878.

4. Otto, R.: Pflüger's Arch. f. d. ges. Physiol. 36:12, 27, 1885.

5. Schwinger, W.: Untersuchungen über den Hämoglobin Gehalt u. d. Zahl der rothen und weissen Blutkörperchen, Pflüger's Arch. f. d. ges. Physiol. 72: $299,338,1898$.

6. Schiff, E.: Ztschr. f. Heilk. 11:17, 1890; ibid. 10:, 1890.

7. Fehrsen, O. M.: Hemoglobin and Corpuscular Content of the Blood of the Newborn, J. Physiol. 30:322, 1903.

8. Woino and Dransky: Beiträge zur Morphologie des Blutes der Neugeborenen. Dissertation, St. Petershurg, 1891. 
In my own series of forty-one cases, I found an average of 7,630,000. Thirty-seven were taken at the time of delivery and four within two hours of delivery. Ten cases were counted on the second, eighth and fourteenth days, with an average of $6,260,000$.

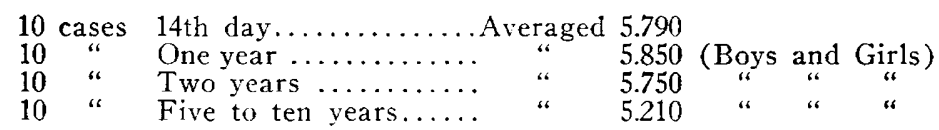

The highest count was 9,610,000 and the lowest was 5,060,000. The findings are expressed graphically in Figure 1, which shows, in solid black, the number of grams of hemoglobin per hundred c.c. in persons ranging in age from 1 to 76 years; and in the curved line, the average erythrocyte count at the same ages. In Figure 2, lines 1, 2 and 3 represent the average, maximum and minimum red blood corpuscle count in a series of forty-one cases. Lines A, B and C show the average, maximum and minimum of hemoglobin, represented by the number of grams of hemoglobin per hundred c.c. of blood.

The hemoglobin richness of the individual red corpuscles is known as its color index. The amount of coloring matter, i.e., hemoglobin, expressed in grams per hundred cubic centimeters, in normal blood, is considered to represent 100 per cent. The average normal red cell count, i. e., 5,000,000 for males and 4,500,000 for females, is considered 100 per cent. The color index is determined by dividing the percentage of hemoglobin by the percentage of red cells. In normal blood the color index is 1 .

It is at once evident that four factors enter into each estimation of color index. Two of them are constants and two of them are variables, which must be accurately determined in each case. The constants are: (a) The normal average number of red cells per cubic millimeter of blood; (b) the normal average number of grams of hemoglobin per hundred cubic centimeters of blood. The variables are: (c) The actual number of red blood corpuscles per cubic millimeter of blood; (d) the actual number of grams of hemoglobin per hundred cubic centimeters of blood in any case under consideration.

If the results of different observers are to be compared, the same standards for constants must be employed. The averages that are recognized in the computation of color index in adults cannot be employed in determining the color index of children. It is immediately manifest, when one consults the hemoglobin values as established by Williamson's table, ${ }^{9}$ that the determination of color index in children is only possible when the proper number of grams of hemoglobin for the age of the child is employed as 100 per cent. Similarly, the average

9. Williamson: Arch. Int. Med. 18:505 (Oct.) 1916. 




Fig. 2.-Lines A, B and C indicate the average amount of hemoglobin, and the average amount for those having more than the average and also for those having less than the average, for males ranging in age from 1 day to over 76 years. Lines 1,2 and 3 show the average number of erthyrocytes and the average number for those having more than the average and for those having less than the average. 
number of red cells obtaining for that age must likewise be employed as representing 100 per cent. In adult males the ordinary procedure of using $5,000,000$ reds and $16 \mathrm{gm}$. hemoglobin is so nearly constant that these figures may be considered normal and will not give appreciable variations. The actual normal fluctuations in early life make the use of any average impossible.

\section{CONCLUSIONS}

1. The red blood count in a series of forty-one infants, in thirtyseven of whom it was taken at time of delivery, averaged 7,630,000.

2. The blood count in children 1 and 2 years of age is somewhat higher than in the adult, this being in marked contrast to the great drop in hemoglobin which is shown in Williamson's table.

3. Inasmuch as the curves of corpuscles and the hemoglobin do not run parallel to each other, the question is raised as to whether the low hemoglobin values are to be regarded as strictly normal or whether it might be altered by a different plan of infant feeding.

4. The norm employed in determining the color index of adults does not apply in determining the color index of children under 10 years of age. 